\title{
"Incidence of Cancer in Tirunelveli Medical College and Hospital-A Five Years Cancer Surveillance Project"
}

\author{
Dr.K.Usha ${ }^{1}$, Dr.J.Suresh Durai ${ }^{2}$ \\ ${ }^{I}$ Department of Pathology, Tirunelveli Medical College,Tamil Nadu, India. \\ ${ }^{2}$ Department of Pathology, Tirunelveli Medical College,Tamil Nadu, India.
}

\begin{abstract}
Worldwide, cancer is the second leading cause of death next to cardiovascular disease. It was estimated that in the year of 2008, over 12.7 million new cancer cases have occurred worldwide and 7.6 million people died due to cancer. It accounted for around 20\% of all deaths in the year of 2008. Environmental factors are responsible for most of the cancers, in which, modifiable risk factors play a major causative role and these are avoidable. The main risk factors associated with cancers are tobacco use, alcohol consumption, infections, dietary habits and physical inactivity. Tobacco use accounts for $50 \%$ of all cancers in males.
\end{abstract}

Keywords: Malignancy, Squamous cell carcinoma, histopathological study, incidence.

\section{Introduction}

Cancer is a group of diseases which is characterized by an abnormal proliferation of cells, which invade adjacent tissues and spread to distant organs. If the tumour has progressed beyond the curable stage it causes even death (Vinay Kumar et al 2010) ${ }^{1}$. Cancer can be broadly divided into three categories on the basis of cell genesis: (a) Carcinomas, that arise from epithelial cells (e.g. lining of mouth, esophagus, intestines, skin and uterus); (b) Sarcomas, which arise from mesodermal cells (e.g. fibrous tissue, fat and bone); and (c) Lymphomas, myeloma and leukemias arising from the hematopoietic cells and immune system (Vinay Kumar et al 2010) ${ }^{1}$.

In India, the International Agency for Research on Cancer (IARC) estimated around 635000 people died due to cancer in 2008, representing around $8 \%$ of all estimated global cancer deaths and around $6 \%$ of all deaths in India. Absolute number of new cancer cases is increasing rapidly due to urbanization, industrialization, lifestyle changes, population growth and ageing (Rajesh Dikshit et al 2012) ${ }^{2}$. The Indian council of medical research (ICMR) initiated the cancer registration network through the national cancer registry programme (NCRP) and commenced a network of cancer registries in various regions of the country.

The stated objectives of NCRP is,

$>$ Provide an idea of the pattern of cancer in the area

$>$ To undertake epidemiological research through cohort and case control studies based on registry data

$>$ Helps to formulate strategies for national cancer control programme

> Cancer registration and epidemiology needs human resource development (Usha K. Luthra et al 1993) ${ }^{3}$.

The cancer registry has been collecting all necessary data pertaining to cancer patients in a prescribed format and with specified guidelines. The collected data is stored in a computer. All malignant neoplasms are registered and classified according to the International Classification of Disease for Oncology (ICDO) (Usha K. Luthra et al loc .cit 1993) ${ }^{3}$. The methods of diagnosing cancer patients differ between pathological laboratory and private and government hospitals. The core proforma consists of name of the patient, age, sex, date of birth, address, name of their parents and marital status( if married) -mainly for cross checking the duplicate registration. In addition to this, the topography, morphology of tumor and the date of diagnosis should also be included. The coding has to be done as per the ICD-O (N.K. Ganguly et al 2006) ${ }^{4}$.

The diagnostic information and coding should be checked by a principal investigator (pathologist or radiotherapist) of the centre. If the primary site of tumor is not known, the treating clinician should be contacted for details (N.K. Ganguly et al 2006 loc. cit) ${ }^{4}$. In our institution, the Department of Pathology -Tirunelveli Medical College, co- ordinated with National Cancer Registration Programme and correlated hospital based cancer surveillance project for a period of three years from 2001-2003. The present study is a continuation of the hospital based cancer registry programme and focuses on analysis of cancer trends and patterns in Tirunelveli Medical College. 
Aim of the Study

1) To know the pattern of cancer for a period of 5 years by hospital based cancer surveillance as per International Classification of Disease-for Oncology (ICD-O)

2) Observation done at Tirunelveli Medical College and hospital for a period of five years from 2007 to 2011.

3) To find out the incidence of cancer among males and females.

4) To assess the age and sex distribution of cancers.

5) To analyse the pattern of emerging new cancer types.

\section{Materials And Methods}

\section{Study area and Period:}

Tirunelveli Medical College and Hospital, from January 2007 to December 2011.

\section{Study Population:}

General population who attended in outpatient department, admitted as inpatient and diagnosed as having malignancy.

\section{Methods of Study:}

Information regarding the incidence of cancer was obtained from the biopsy, cytology and hematology report register in the Department of Pathology at Tirunelveli Medical College and Hospital.

A prediagnosed questionnaire was prepared for data collection.

\section{Duration of Study:}

This study was observed over a period of 5 years from 2007 to 2011.

\section{Inclusion Criteria:}

Out of fine needle aspiration cytology study, haematological study and histopathological study, histopathological data was taken an inclusive criteria. Between incisional and excisional biopsy of histopathological study, excisional biopsy was considered as an inclusive criteria.

\section{Exclusion Criteria:}

Compared to histopathological study, fine needle aspiration cytology is less significant. In such cases FNAC was considered as exclusion criteria to avoid duplication. In peripheral smear study versus bone marrow aspiration study, peripheral smear study is less significant. Hence it was excluded to avoid duplication.

\section{Observation And Results}

During the year of 2007 to 2011, there were totally 36558 biopsies received in the Department of Pathology in Tirunelveli Medical College and Hospital from both outpatient and inpatients. Out of which, 4162 (11.38\%) cases were diagnosed microscopically as cancer, and the remaining cases $(88.62 \%)$ were diagnosed as non tumoral lesions and Benign tumors. The following chart depicts the total incidence of cancer (fig: 1)

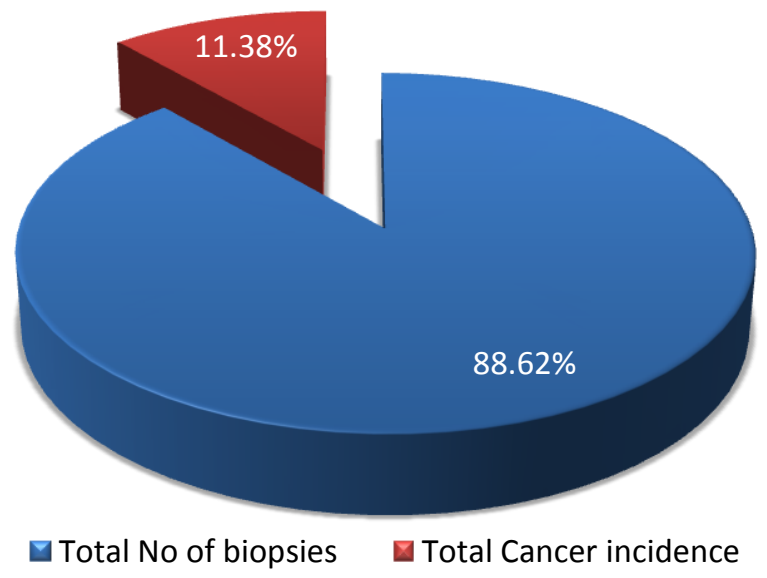

Figure: 1. Total incidence of cancer from 2007 to 2011. 
"Incidence of Cancer in Tirunelveli Medical College and Hospital-A Five Years Cancer Surveillance ....

The data was analyzed by the standard statistical software namely PASW (Predictive and Analysis Soft Ware) Statistics-18, the so called SPSS. The trends of increase from base year (2007) through end year (2011) were analyzed in terms of percentages and interpreted by $\chi^{2}$ (Chi-square) Test. The gender and child wise trends of age incidence were analyzed and interpreted by general linear model (Two ways ANOVA). The age of incidence between the gender was analyzed by Students unpaired' $t$ ' test. The trends of sites of occurrence and diagnosis were analyzed in terms of percentages. The P-Value $<0.05$ was considered as statistically significant under two-tailed situation. The total cancer incidence from 2007 to 2011 were 4162 cases (11.38\%). The following table and figure depicts the cancer incidence from 2007 to 2011.

Table-1.Total no of cancer incidence from 2007 to 2011

\begin{tabular}{|l|l|l|l|}
\hline YEAR & NO OF BIOPSIES & NO OF CANCERS & \% \\
\hline 2007 & 5941 & 661 & 11.1 \\
\hline 2008 & 6431 & 675 & 10.5 \\
\hline 2009 & 7746 & 837 & 10.8 \\
\hline 2010 & 8091 & 929 & 11.5 \\
\hline 2011 & 8349 & 1060 & 12.7 \\
\hline Total & 36558 & 4162 & 11.38 \\
\hline
\end{tabular}

The above table (1) depicts the yearly cancer incidence. During the year 2007, there were totally 661 cases (11.1\%) diagnosed microscopically as cancer, followed by 675 cases $(10.5 \%)$ in 2008,837 cases $(10.8 \%)$ in 2009,929 cases (11.5\%) in 2010 and 1060 cases (12.7\%) in 2011. This reveals that the percentages of distribution of cancer cases were gradually increasing from base year to end year.

Trends of cancer incidence:

The trends of cancer incidence from base year to end year (2007-2011).

Table-2. Gender wise incidence of cancer (2007 to 2011)

\begin{tabular}{|c|c|c|c|c|c|c|c|c|c|c|c|}
\hline \multirow[t]{2}{*}{ Gender } & \multicolumn{2}{|c|}{2007} & \multicolumn{2}{|c|}{2008} & \multicolumn{2}{|c|}{2009} & \multicolumn{2}{|c|}{2010} & \multicolumn{2}{|l|}{2011} & \multirow[t]{2}{*}{ Total } \\
\hline & No & $\%$ & No & $\%$ & No & $\%$ & No & $\%$ & No & $\%$ & \\
\hline Males & 234 & 35.4 & 237 & 35.1 & 394 & 47.1 & 427 & 46.0 & 498 & 47.0 & 1790 \\
\hline Females & 413 & 62.5 & 426 & 63.1 & 424 & 50.6 & 484 & 52.1 & 545 & 51.4 & 2292 \\
\hline Children & 14 & 2.1 & 12 & 1.8 & 19 & 2.3 & 18 & 1.9 & 17 & 1.6 & 80 \\
\hline Total & 661 & 15.9 & 675 & 16.2 & 837 & 20.1 & 929 & 22.3 & 1060 & 25.5 & 4162 \\
\hline$\square^{2}$ & \multicolumn{10}{|c|}{50.504} & \\
\hline d.f & \multicolumn{10}{|l|}{8} & \\
\hline Significance & \multicolumn{10}{|c|}{$P<0.001$} & \\
\hline
\end{tabular}

The gender wise incidence of cancer from base to end year is shown in the above table(2). The table (2) showed that the incidence of cancer among the males were increasing steadily from $35.4 \%$ to $47 \%$ and the increase was statistically highly significant $(\mathrm{P}<0.001)$. Among the females, the cancer incidence is fluctuating from $2007(62.5 \%)$ to $2011(51.4 \%)$ and the same was also statistically significant $(\mathrm{P}<0.001)$. But, among children the incidence was fluctuating in between $2.1 \%$ to $1.6 \%$. The total incidence of cancer cases from base to end was $15.9 \%$ to $25.5 \%$.The increase was steady and statistically very highly significant $(\mathrm{P}<0.001)$. During the year 2007 , totally 647 adult cases were diagnosed as cancer, Out of which, $65.69 \%$ were females, the remaining $34.31 \%$ were males. In the year of 2008 totally 663 adult cases (males-40.87\%, females $-59.13 \%$ ) were diagnosed with cancer. In the year of 2009 totally 818 adult cases (males- $48.18 \%$, females-51.82\%) were diagnosed as cancer, similarly in the year of 2010 and 2011 totally 911 (males-46.76\%, females-53.24\%) 1043(males-47.75\%females-52.25\%) adult cases were diagnosed as cancer in respectively.Table 2 showed that in the gender wise incidence of cancer in adults and children, $55.08 \%$ (2292 cases) were females, $43 \%$ (1790cases) were males and the remaining $1.92 \%$ (80cases) were children.

\section{Trends of cancer incidence based on age:}

The incidence of cancer cases were analyzed according to their age. The mean age of males increased from 2007 (mean age-54.9, +/_14.1) to 2010 (mean age-58.5+/-12.4) and decreased in 2011(mean age-56.9+/-12.1). The mean age of females was fluctuating from 2007 (mean age-51.4, SD-12.4) through 2011(mean age-52.3+/-13.4). The mean age of males between the years was not statistically significant except for the year 2010 ( $P>0.05)$. The mean age of women and children was also not statistically significant between the years $(\mathrm{P}>0.05)$. 
"Incidence of Cancer in Tirunelveli Medical College and Hospital-A Five Years Cancer Surveillance ....

Incidence of cancer based on Gender:

The incidence of cancer among the male and female age groups (in years) was compared.

Table -3. Comparison of cancer incidence between male and female for five years period (2007-2011).

\begin{tabular}{|l|l|l|l|l|l|l|l|}
\hline Gender & \multirow{2}{*}{$\mathbf{N}$} & \multicolumn{2}{|l|}{ Age (years) } & Difference between means & 't' & d.f & Significance \\
\cline { 3 - 4 } & & Mean & SD & & & & \\
\hline Males & 1790 & 56.9 & 12.9 & 4.7 & 9.182 & 4080 & $\mathrm{P}<0.001$ \\
\hline Females & 2292 & 52.2 & 18.3 & & & \\
\hline
\end{tabular}

The mean age of cancer incidence among the males and females were 56.9 12.9 and 52.2 \pm 18.3 .The difference of age between male and female was statistically significant $(\mathrm{P}<0.001)$.

Trends of cancer Incidence based on site:

The following table (4) shows the incidence of cancer categorized according to the topographic sites from 2007 to 2011.

Table- 4.Topographic Site of cancer incidence, 2007-2011

\begin{tabular}{|c|c|c|c|c|c|}
\hline 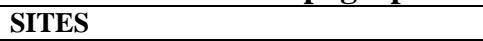 & 2007 & 2008 & 2009 & 2010 & 2011 \\
\hline $\begin{array}{l}\text { Head \& Neck } \\
(\text { C00-12,C30-32) }\end{array}$ & 107 & 124 & 188 & 279 & 347 \\
\hline 1)Oral cavity (C06.9) & 46 & 64 & 80 & 100 & 137 \\
\hline 2)Oropharynx (C10) & 30 & 22 & 41 & 62 & 68 \\
\hline 3)Nasopharynx (C11) & 4 & 8 & 7 & 15 & 12 \\
\hline 4)Hypopharynx (C13) & 8 & 13 & 25 & 48 & 57 \\
\hline 5)Larynx (C32) & 5 & 5 & 22 & 31 & 47 \\
\hline 6)Salivary gland (C08) & 12 & 12 & 11 & 22 & 21 \\
\hline 7)Ear \& Eye (C44.2\&C69) & 2 & 0 & 2 & 1 & 5 \\
\hline Breast (C50) & 106 & 111 & 101 & 125 & 116 \\
\hline Thyroid (C73) & 42 & 38 & 46 & 45 & 62 \\
\hline GIT (C15-26) & 84 & 90 & 124 & 77 & 118 \\
\hline 1)Esophagus (C15) & 4 & 15 & 17 & 5 & 14 \\
\hline 2)OGJ (C16.0) & 0 & 6 & 5 & 1 & 0 \\
\hline 3)Stomach (C16) & 34 & 35 & 43 & 22 & 32 \\
\hline 4)Small intestine (C17) & 2 & 1 & 1 & 3 & 4 \\
\hline 5)Colorectum(C18\&C20) & 26 & 13 & 29 & 21 & 39 \\
\hline 6)Anus (C21) & 4 & 3 & 7 & 5 & 9 \\
\hline 7))GIT NOS(C26.9) & 14 & 17 & 22 & 20 & 20 \\
\hline FGT(C51-58) & 157 & 177 & 150 & 149 & 170 \\
\hline 1)Endometrium (C54.1) & 7 & 4 & 7 & 4 & 6 \\
\hline 2)Cervix (C53) & 134 & 144 & 122 & 112 & 141 \\
\hline 3)Fallopian tube (C57.0) & 0 & 0 & 0 & 1 & 1 \\
\hline 4)Ovary (C56) & 11 & 16 & 14 & 23 & 17 \\
\hline 5)Vagina (C52) & 3 & 11 & 4 & 7 & 4 \\
\hline 6)Vulva (C51) & 2 & 2 & 3 & 2 & 1 \\
\hline MGT (C60-63) & 18 & 22 & 27 & 33 & 37 \\
\hline 1)Penis (C60) & 13 & 14 & 18 & 17 & 25 \\
\hline 2)Prostate (C61) & 5 & 5 & 6 & 13 & 9 \\
\hline 3)Testis (C62) & 0 & 3 & 3 & 3 & 3 \\
\hline Urinary Tract (C64-68) & 22 & 26 & 14 & 18 & 26 \\
\hline 1)Kidney (C64) & 4 & 10 & 1 & 6 & 4 \\
\hline 2)Ureter (C66) & 0 & 0 & 0 & 0 & 1 \\
\hline 3)Bladder (C67) & 18 & 16 & 13 & 12 & 20 \\
\hline Bone\&SoftTissue & 4 & 6 & 14 & 4 & 2 \\
\hline Skin (C44) & 22 & 6 & 28 & 25 & 16 \\
\hline Lymph Nodes (C77) & 56 & 36 & 48 & 67 & 58 \\
\hline Hematopoietic System (C42) & - & 14 & 20 & 12 & 26 \\
\hline Other Sites & 43 & 25 & 77 & 95 & 82 \\
\hline Total & 661 & 675 & 837 & 929 & 1060 \\
\hline
\end{tabular}

The above table (4) depicts the trends of cancer incidence in respect to sites. Cancer patterns vary not only throughout the world but also in different population groups within the same country. The above table (4) shows year wise categorization of cancer sites which includes Head neck (oral cavity, lip, cheek, tongue, tonsil, mouth, oropharynx, nasopharynx, hypopharynx, larynx, salivary glands, eye and ear), gastrointestinal tract (esophagus, 
"Incidence of Cancer in Tirunelveli Medical College and Hospital-A Five Years Cancer Surveillance ....

stomach, small intestine, colon and anal canal), female genital tract (uterus, cervix, ovary, fallopian tube, vagina and vulva), male genital tract (testis, penis and prostate), urinary tract (kidney, ureter and urinary bladder), lymph node and other sites including lung, brain, adrenal bone \& soft tissue, skin and hematopoietic system. In which the most commonly observed cancer types were squamous cell carcinoma, Adenocarcinoma and invasive ductal carcinomas.

(All sites C00-C96)

Table. 5. The top ten leading cancer sites in 2007, both Male \& Female.

\begin{tabular}{|l|l|l|l|}
\hline RANK & SITE & NO OF CANCERS & \% \\
\hline 1 & Cervix (C53) & 134 & 20.27 \\
\hline 2 & Head \& Neck(C00-14\&C30-32) & 107 & 16.19 \\
\hline 3 & Breast (C50) & 106 & 16.04 \\
\hline 4 & GIT (C15-C26) & 84 & 12.71 \\
\hline 5 & Thyroid (C73) & 42 & 6.35 \\
\hline 6 & Lymph Nodes -Primary (C77) & 32 & 4.84 \\
& & & \\
\hline 7 & Lymph Nodes -Secondary(C77) & 24 & 3.63 \\
\hline 8 & Urinary Tract (C64-68) & 22 & 3.33 \\
\hline 9 & Skin (C44) & 22 & 3.33 \\
\hline 10 & Other Sites & 88 & 13.31 \\
\hline & Total & 661 & 100 \\
\hline
\end{tabular}

The table (5) - gives the ten leading sites of cancer, for both male and female in the year of 2007. The system wise predominant cancer sites during 2007 was cervix (C53.9) and it is the first leading cancer site (134 cases,20.27\%), followed by head \& neck (C00 to C14.2) (107cases,16.19\%), breast(C50.9) (106cases,16.04\%), GIT(C15-C26) (84cases, 12.71\%), thyroid(C73.9) (42cases,6.35\%), lymph node(C77.9), (both primary4.84\% and secondary3.63\%), urinary tract (C64-C68) (22cases,3.33\%), skin (C44.9) (except labia majora, vulva, penis \& scrotum)(22cases, $3.33 \%) \&$ other sites(C00-C96)(13.31\%).

Table.6.The top ten leading cancer sites for 2008 , both male and female

(All sites C00-C96)

\begin{tabular}{|l|l|l|l|}
\hline RANK & SITE & NO OF CANCERS & $\%$ \\
\hline 1 & Cervix (C53) & 144 & 21.33 \\
\hline 2 & Head \& Neck (C00-14,C30-32) & 124 & 18.37 \\
\hline 3 & Breast (C50) & 111 & 16.44 \\
\hline 4 & GIT (C15-C26) & 90 & 13.33 \\
\hline 5 & Thyroid (C73) & 38 & 5.63 \\
\hline 6 & Urinary Tract (C64-68) & 26 & 3.85 \\
\hline 7 & Male Genital Tract (60-63) & 22 & 3.26 \\
\hline 8 & Lymph Nodes- Primary(C77) & 19 & 2.82 \\
\hline 9 & Lymph Nodes- Secondary (C77) & 17 & 2.52 \\
\hline 10 & Lung (C34.9) & 15 & 2.22 \\
\hline & Other Sites & 69 & 10.23 \\
\hline & Total & 675 & 100 \\
\hline
\end{tabular}

The table (6): gives the ten leading sites of cancer, in both male and female in the year of 2008. The system wise predominant cancers sites during 2008 was cervix (C53.9), it is the most leading cancer site (144cases,21.33\%), followed by Head \& Neck (C00 TO C14.2) (124cases,18.37\%), breast (C50.9) (111cases, 16.44\%), GIT (C15-C26) (90cases,13.33\%), thyroid (C73.9) (38cases,5.63\%), urinary tract (C64-C68)(26cases,3.85\%), MGT(C63.9) (22cases,3.26\%), lymph nodes primary (C77.9)(19cases,2.82\%), lymph nodes secondary (17cases,2.52\%), lung (C34.9) (15cases,2.22\%) and other sites (80cases, $11.85 \%)$.

Table.7.The top ten leading cancer sites for 2009 , both male and female

\begin{tabular}{|l|l|l|l|}
\hline RANK & SITE & NO OF CANCERS & \% \\
\hline 1 & Head \& Neck (C00-C14\& C30-32) & 188 & 22.46 \\
\hline 2 & GIT (C15-C26) & 124 & 14.81 \\
\hline 3 & Cervix (C53) & 122 & 14.57 \\
\hline 4 & Breast (C50) & 101 & 12.06 \\
\hline 5 & Thyroid (C73) & 46 & 5.50 \\
\hline 6 & Skin (C44) & 28 & 3.35 \\
\hline 7 & Male Genital Tract(C60-63) & 27 & 3.23 \\
\hline
\end{tabular}


"Incidence of Cancer in Tirunelveli Medical College and Hospital-A Five Years Cancer Surveillance ....

(All sites C00-C96)

\begin{tabular}{|l|l|l|l|}
\hline 8 & Lymph Node- Primary(C77) & 25 & 2.99 \\
\hline 9 & Lymph Node- Secondary(C77) & 23 & 2.75 \\
\hline 10 & Lung(C34.9) & 23 & 2.75 \\
\hline 11 & Hematopoietic(C42) & 20 & 2.39 \\
\hline & Other Sites & 110 & 13.14 \\
\hline & Total & 837 & 100 \\
\hline
\end{tabular}

The table (7) - gives the ten leading sites of cancer, in both male and female in the year of 2009. The system wise predominant cancer sites during 2009 were head \& neck (C00 TO C14.2) (188cases, 22.46\%), followed by GIT (C15-C26) (124cases,14.81\%), cervix (C53.9) (122cases,14.57\%), breast (C50.9) (10lcases,12.06\%), thyroid (C73.9) (46cases,5.50\%), skin (28cases,3.35\%), MGT (C63.9) (27cases,3.23\%), lymph nodes primary (C77.9)(25cases,2.99\%), lymph nodes secondary (23cases,2.75\%), lung (C34.9) (23cases,2.75\%), hematopoietic system(C42) (20cases, $2.39 \%)$ and other sites (110cases, 13.14\%).

\begin{tabular}{|l|l|l|l|}
\hline RANK & SITE & NO OF CANCERS & $\%$ \\
\hline 1 & Head \& Neck (C00-C14,C30-33) & 279 & 30.03 \\
\hline 2 & Breast (C50) & 125 & 13.46 \\
\hline 3 & Cervix (C53) & 112 & 12.05 \\
\hline 4 & GIT (C15-C26) & 77 & 8.29 \\
\hline 5 & Thyroid (C73) & 45 & 4.84 \\
\hline 6 & Lymph Node- Primary(C77) & 38 & 4.09 \\
\hline 7 & Lung (C34.9) & 36 & 3.88 \\
\hline 8 & Male Genital Tract (C62-C63) & 33 & 3.55 \\
\hline 9 & Lymph Nodes -Secondary (C77) & 29 & 3.12 \\
\hline 10 & Skin (C44) & 25 & 2.69 \\
\hline & Other Sites & 130 & 14.00 \\
\hline & Total & 929 & 100 \\
\hline
\end{tabular}

Table.8.The top ten leading cancer sites for 2010 , both male and female

(All sites C00-C96)

The table (8): gives the ten leading sites of cancer, in both male and female in the year of 2010. The system wise predominant cancer sites during 2010 were head \& neck(C00 to C14.2) (279cases,30.03\%), followed by breast (C50.9) (125cases,13.46\%), cervix(C53.9) (112cases,12.05\%), GIT (C15-C26) (77cases,8.29\%), thyroid(C73.9) (45cases,4.84\%), lymph nodes primary(C77.9) (38cases,4.09\%), lung(C34.9) (36cases,3.88\%), MGT(C63.9) (33cases,3.55\%), lymph nodes secondary(29cases,3.12\%), skin(25cases, $2.69 \%$ ), and other sites (130cases, $14 \%$ ).

Table.9. The top Ten leading cancer sites for 2011, both male and female

(All sites C00-C96)

\begin{tabular}{|l|l|l|l|}
\hline RANK & SITE & NO OF CANCERS & \% \\
\hline 1 & Head \&Neck(C00-C14.2) & 347 & 32.74 \\
\hline 2 & Cervix(C53) & 141 & 13.30 \\
\hline 3 & GIT(C15-C26) & 118 & 11.14 \\
\hline 4 & Breast(C50) & 116 & 10.94 \\
\hline 5 & Thyroid(C73) & 62 & 5.85 \\
\hline 6 & Lymph Nodes Primary(C77) & 41 & 3.87 \\
\hline 7 & Lung(C34.9) & 38 & 3.58 \\
\hline 8 & Male Genital Tract(C62-C63) & 37 & 3.49 \\
\hline 9 & Urinary Tract (C64-C69) & 26 & 2.45 \\
\hline 10 & Hematopoietic System (C42) & 26 & 2.45 \\
\hline & Other Sites & 108 & 10.19 \\
\hline & Total & 1060 & 100 \\
\hline
\end{tabular}

The table (9)- gives the ten leading sites of cancer, in both male and female in the year of 2011. The system wise predominant cancer sites during 2011 were head \& neck (C00 TO C14.2) (347 cases,32.74\%), followed by cervix (C53.9)(141cases,13.30\%), GIT (C15-C26) (118cases,11.14\%), breast (C50.9) (116cases,10.94\%), thyroid (C73.9) (62cases,5.85\%), lymph node -primary (C77.9)(41cases, 3.87\%), lung (C34.9) (38cases, 3.58\%,) MGT (C63.9) 
"Incidence of Cancer in Tirunelveli Medical College and Hospital-A Five Years Cancer Surveillance ....

(37cases, 3.49\%), urinary tract (26cases, $2.45 \%)$, hematopoietic system (26cases, $2.45 \%)$ and other sites (108cases, $10.19 \%)$.

Table -10: Comparison of cancer sites among adults between gender

\begin{tabular}{|c|c|c|c|c|}
\hline SITE & $\begin{array}{l}\text { No } \quad \text { Of } \\
\text { Cancers In } \\
\text { Male } \\
\end{array}$ & $\begin{array}{ll}\text { No } & \text { Of } \\
\text { Cancer } & \text { In } \\
\text { Female } & \\
\end{array}$ & $\begin{array}{l}\text { Total No Of } \\
\text { Cancer }\end{array}$ & $\begin{array}{ll}\text { Male } & : \\
\text { Female } & \\
\text { Ratio } & \\
\end{array}$ \\
\hline $\begin{array}{l}\text { Cervix(C53) } \\
\text { (C) }\end{array}$ & - & 653 & 653 & - \\
\hline Head\& Neck(C00-C14.2) & 715 & 317 & 1032 & $2.2: 1$ \\
\hline Breast(C50) & 15 & 544 & 559 & $1: 36$ \\
\hline GIT(C15-26) & 275 & 217 & 492 & $1.3: 1$ \\
\hline Thyroid(C73) & 58 & 174 & 232 & $1: 3$ \\
\hline Lymphnode Primary(C77) & 73 & 46 & 119 & $1.6: 1$ \\
\hline LymphnodeSecondary(C77) & 77 & 33 & 110 & $2.3: 1$ \\
\hline Urinary Tract(C64-C68) & 77 & 24 & 101 & $3.2: 1$ \\
\hline Male Genital Tract(62-C63) & 134 & - & 134 & - \\
\hline Lung(C34.9) & 95 & 24 & 119 & $4: 1$ \\
\hline HematopoieticSystem(C42) & 34 & 18 & 52 & $1.9: 1$ \\
\hline Skin(C44) & 54 & 42 & 96 & $1.3: 1$ \\
\hline Other Sites & 183 & 200 & 383 & \\
\hline
\end{tabular}

(All sites C00-C96)

The above table (10) shows the comparison between male and female cancer incidence sites, which revealed that statistically breast cancer among the female (23.7) was significantly greater than males (0.8) (M:F-1:36). Cervical cancer was exclusively among the females. Male genital tract cancers were exclusively among males. Statistically the following sites of cancer such as head\& neck(M:F-2.2:1), gastrointestinal tract(M:F-1.3:1), lymph node primary(M:F-1.6:1), lymph node secondary(M:F-2.3:1), urinary tract(M:F-3.2:1), lung(M:F-4:1), skin(M;F-1.3:1), and hematopoietic system (M:F-1.9:1) among males was significantly greater than that of females $(\mathrm{P}<0.001)$. The incidence of thyroid cancer among females was statistically significantly greater than that of males (M:F-1:3) $(\mathrm{P}<0.001)$.

Table-11. Comparison of cancer sites between adults and Children, 2007-2011

\begin{tabular}{|l|l|l|l|l|l|l|}
\hline \multirow{2}{*}{ Site } & \multicolumn{2}{|l|}{ Adult } & \multicolumn{2}{l}{ Children } & Z & \multirow{2}{*}{ Significance } \\
\cline { 2 - 6 } & No & $\mathbf{\%}$ & No & $\mathbf{\%}$ & & \\
\hline Adrenal\& parasympathetic ganglion & 3 & 0.1 & 2 & 2.5 & - & - \\
\hline Hematopoietic system & 52 & 1.4 & 20 & 25.2 & 4.892 & $\mathrm{P}<0.001$ \\
\hline Brain & 11 & 0.4 & 2 & 2.5 & 1.259 & $\mathrm{P}>0.05$ \\
\hline GIT & 492 & 12 & 2 & 2.5 & - & - \\
\hline Kidney & 17 & 0.4 & 7 & 8.8 & 1.745 & $\mathrm{P}>0.05$ \\
\hline Lymph nodes-primary & 119 & 2.9 & 36 & 45 & 6.09 & $\mathrm{P}<0.001$ \\
\hline Head and neck & 1032 & 25.2 & 3 & 3.2 & 0.044 & $\mathrm{P}>0.05$ \\
\hline Ovary & 77 & 1.9 & 3 & 3.7 & 0.172 & $\mathrm{P}>0.05$ \\
\hline Skin & 96 & 2.3 & 1 & 1.2 & 0.088 & $\mathrm{P}>0.05$ \\
\hline Thyroid & 229 & 5.6 & 1 & 1.2 & 0.352 & $\mathrm{P}>0.05$ \\
\hline Others & 1954 & 47.9 & 3 & 3.7 & & \\
\hline Total & 4082 & 100.0 & 80 & 100 & & \\
\hline
\end{tabular}

The cancer sites of adults and children were compared in the above table- (11). Statistically the hematopoietic malignancy (25\%) and lymph nodes primary $(39 \%)$ were significantly more among children, than adults $(\mathrm{P}<0.001)$. Nearly three fourth of the children were presented with hematopoietic malignancy and malignant lymphoma. The incidence of cancer in other sites among the children is statistically not significant when compared with adults.

Table: 12- Observed ten leading cancer sites from 2007 to 2011.

\begin{tabular}{|l|l|l|l|l|l|l|}
\hline Site & 2007 & 2008 & 2009 & 2010 & 2011 & TOTAL \\
\hline Head \&Neck & 107 & 113 & 188 & 279 & 347 & 1034 \\
\hline Cervix & 134 & 144 & 122 & 112 & 141 & 653 \\
\hline Breast & 106 & 111 & 101 & 125 & 116 & 559 \\
\hline GIT & 84 & 90 & 124 & 77 & 118 & 493 \\
\hline Thyroid & 42 & 38 & 46 & 45 & 62 & 233 \\
\hline Lymph Nodes- Primary & 32 & 19 & 25 & 38 & 41 & 155 \\
\hline MGT & 15 & 22 & 27 & 33 & 37 & 134 \\
\hline
\end{tabular}




\begin{tabular}{|l|l|l|l|l|l|l|}
\hline Lung & 7 & 15 & 23 & 36 & 38 & 119 \\
\hline LymphNodes- Secondary & 24 & 17 & 23 & 29 & 17 & 110 \\
\hline Urinary Tract & 22 & 26 & 15 & 19 & 26 & 108 \\
\hline Others & 88 & 80 & 143 & 136 & 117 & 564 \\
\hline Total & 661 & 675 & 837 & 929 & 1060 & 4162 \\
\hline
\end{tabular}

Table (12) showed that head and neck cancer constitute predominant numbers $24.84 \%$ (1034 cases), followed by cervix $-15.69 \%$ (653 cases), breast-13.43\%(559cases), GIT-11.85\%(493cases), thyroid-5.6\%(233 cases), lymph node primary-3.72\%(155 cases), male genital tract-3.22\%(134 cases), lung-2.86\%(119 cases), lymph node secondary$2.64 \%$ (110 cases), urinary tract-2.60\%(108 cases) and others-13.55\%. Table (12) depicts the ten leading cancer sites (2007-2011)showing that, during the period of 2007 to 2008 cervix was the most commonly affected cancer site followed by head and neck, breast, thyroid, GIT and others. During the period of 2009-2011 head and neck is the most common leading site followed by all others including cervix, breast, GIT and other sites.

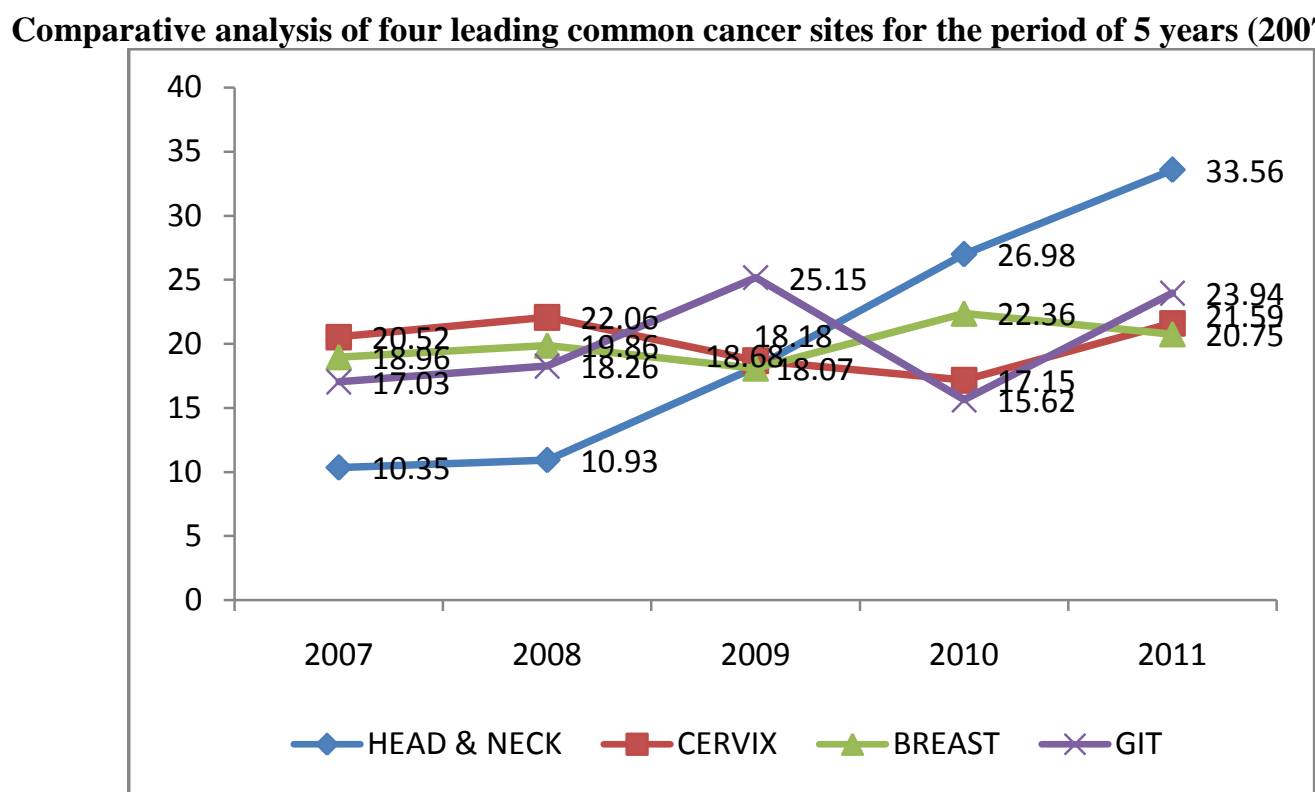

Fig: 2. The four most common cancer sites for the period of five years, 2007 to 2011.

The above fig-(2) depicts the four leading cancer sites for five year period (from 2007 to 2011). The head and neck cancers shows dramatically increasing trend from 2007 to 2011, which is the most common cancer site for past three year duration in our study. The breast cancer shows gradual increase in trends throughout the five years. The cervical and GIT cancers were fluctuating from 2007 to 2011.

Observed incidence of other sites such as thyroid, lymph node primary, MGT, and lung cancers were gradually increasing trend from 2007 to 2011. The new emerging cancer site was gall bladder, which also showed the same increasing trend from $2008-2011$.

\section{Discussion}

This study broadly analyzed the incidence, age, sex, and system wise distribution of cancer presented at our tertiary care centre over a period of five years from 2007 to 2011. The cancers were classified as per The International Classification of Disease for- Oncology (WHO loc. cit 2000) ${ }^{5}$.

Cancer is the common cause of mortality in developed countries and the second common cause of mortality in developing countries (WHO loc.cit 2009b) ${ }^{6}$. The purpose of HBCRs is concerned with collection of information about the cancer cases seen in a particular hospital. Within the hospital, a registry is considered to be an integral part of hospital cancer programme. The information in this form chiefly consists of patient's identification, diagnosis, treatment, clinical staging and demographic information and to ensure the follow up of the patients on the regular basis (J.L. Young HBCRs 1991) ${ }^{7}$.

PBCRs data's may be used to monitor the distribution of advanced stage of cancers and their pattern, in which the strategy for early diagnosis is utilized for controlling the disease progression. The PBCR plays an 
"Incidence of Cancer in Tirunelveli Medical College and Hospital-A Five Years Cancer Surveillance ....

essential role in the improvement of patient care programs. Linkage services of this type of cancer registries for health care providers deliver a cost-effective source of data which are needed for clinical programs, such as i) Follow-up results of a screening program (particularly breast), ii) Data's pertaining to the stage of diagnosis, iii) Data's related to treatment selection is obtained for monitoring the guidelines for clinical treatment and their utilization (Nandakumar A et al 1990-1996) ${ }^{8}$.

The biggest benefit of ICD-O classification dedicated entirely to oncology is that it helps tackle the serious issue of cancer in a much more efficient manner than before. The International Classification code provides a common platform for researchers and oncologists from all over the world to discuss and share the research information which helps to identify the cause of cancer in a big way. Further, owing to the classification, oncologists now have a more precise way of knowing whether a tumour is benign or cancerous. This precise distinction itself is the biggest step towards planning and initiating treatment (WHO loc.cit 2000) ${ }^{5}$.

It is more beneficial if patient needs to be treated in other countries, since the basis for diagnosis will be the same everywhere. The various factors that are taken into consideration for preparing the classification provide a better platform for more definite diagnosis. This classification is more modern and encompasses a lot of modern research that the previous versions were lacking in, thus making it the perfect international benchmark for all oncology studies (WHO loc. cit 2000) . $^{5}$

About 12.7 million cases were estimated to have occurred in 2008 worldwide (Globocan 2008) ${ }^{9}$. In the year of 2009, Around 320500 cancer cases were diagnosed in UK, this equates to about 519 patients per 100000 people every year (UK stats loc. cit 2012) ${ }^{10}$. In India the total number of cases in 2004 were 819354, of these 47.7\% (390809 cases) were male and 52.3\% (42854 cases) were female. This present study also shows similar results out of which 4162 cases were diagnosed as cancer in the five year period from 2007 to 2011, 56\% were females and $44 \%$ were males.

In European study, $56 \%$ cases were found to be in the age group of $>65$ years. Another study which was conducted in UK, showed that more than 3 out of 5 newly diagnosed cancer patients were in the age group of 65 or more, (UK stats loc. cit 2012) ${ }^{10}$. In contrast to this, the present study reveals that only $25 \%$ of people with cancer were above 65 years of age. Another study conducted in Mumbai cancer registry showed that people in the age group 65 years and above contributed to about $35.5 \%$ of the total cases, which also contradicts our present study $(25 \%)$.

In the year 2008, about 12.7 million cancer cases were diagnosed globally, in which $52 \%$ of the total cancer cases were males and $48 \%$ were females (Goodarz Danaei 2012) ${ }^{11}$ (Globocan loc.cit 2008) ${ }^{9}$. This contradicts our study in which we observed in the five year period from 2007 to 2011 that totally $56 \%$ cases with cancers were female and $44 \%$ cases with cancers were male. Another study which was conducted in Mumbai 2006, showed that there were totally 11033 new cases registered for the year 2006, of these $48.5 \%$ were males and $51.5 \%$ cases were females (A.P. Kurkure et al 2006) ${ }^{12}$, this study more or less correlated with our study that females (56\%) were most commonly affected than males (44\%).

Lung cancer is the foremost cancer among both the genders contributing nearly 13percent of the total cancer cases estimated globally in the year 2008. The second most common cancer is the Breast cancer contributing nearly 1.4 percent cases in 2008. In the same year cancer colorectum ranked the third with over 1.2 million cases of cancers diagnosed (Globocan loc.cit 2008) ${ }^{9}$. This study challenged our present study in which we observed that the head and neck cancer is the most common cancer followed by cervical cancers (female), breast cancers (female), gastrointestinal tract cancers and thyroid cancers among both sexes.

In Mumbai 2006, as far as total cases were concerned in males, the lung cancer was found to have higher incidence followed by lymphomas, mouth cancers, prostate cancers and tongue cancers. In females the breast cancers ranked first in incidence followed by cervical cancers, ovarian cancers, lung cancers and leukemia's (A.P. Kurkure et al loc.cit 2006) ${ }^{12}$. Our present study states that the head and neck cancer leads first among males followed by gastrointestinal cancers, male genital tract cancers and lung cancers. In females, cervix is the most common cancers followed by breast, gastrointestinal tract and thyroid. Male preponderance was observed at all sites except breast, thyroid and gallbladder cancers (A.P.Kurkure et al loc.cit 2006) ${ }^{12}$. This correlated with our present study.

In Chennai, most commonly observed cancers were breast followed by cervix, lung and stomach, (R. Swaminathan et al loc.cit 2011) ${ }^{13}$. This contradicts our present study in which we observed head and neck cancers are the most common cancers followed by cervix, breast and thyroid.

ICMR study (1982-2005) has shown that there was an increased incidence of breast cancer (Imran Ali et al loc.cit 2011) ${ }^{14}$. Similarly, our present study showed that the incidence of breast has increased from $19 \%$ (2007) to $21 \%$ (2011). Another study conducted by Swaminathan et al, 2011, showed increased incidence of breast cancer as 
"Incidence of Cancer in Tirunelveli Medical College and Hospital-A Five Years Cancer Surveillance ....

registered by cancer registries from 1982 to 2006 (R. Swaminathan et al loc. cit 2011) ${ }^{13}$. Similarly, this present study observed an increased incidence of breast cancer from 2007(19\%) to 2011(21\%).

In 1988, Delhi cancer registries reported around $25.9 \%$ of cervical cancers per 100000 populations, which reduced to 19.1percent in the year1998 and further declined to 18.9 percent in 2005 (A.P. Kurkure et al loc.cit $2006)^{12}$. In contrast, this present study showed a marginal raise in the occurrence of cervical cancer from $20.5 \%$ to $21.6 \%$ over a five year period (2007-2011).

The Chennai cancer registries report that there is a reduction in the incidence of cancer cervix from $41 \%$ of patients /100000 populations in 1982, to 33.4 percent in 1991 and has been further declined to 20.0 percent in 2005 (R. Swaminathan et al loc.cit 2011) ${ }^{13}$. In contrast, our present study revealed marginal increase in incidence from $20.5 \%$ (2007) to $21.6 \%$ (2011).

The head and neck cancers, tongue cancers and laryngeal cancers showed an increasing incidence from 1982 to 2006 in consistent with the Chennai cancer registry reports (R. Swaminathan et al 2011) ${ }^{13}$. Similarly, this present study observed that the incidence of head and neck cancers especially tongue and laryngeal cancers were increasing from 2007 to 2011.

Study which was conducted by Swaminathan et al $(2011)^{13}$, showed that the incidence for oral cancers (excluding tongue) were decreasing from 1982 to 2006. In contrast, this present study revealed an increased incidence from 2007 to 2011.

Other cancers such as leukemia, lung cancers and GIT cancers (colorectal) have increased in incidence from 1982 to 2006 (R.Swaminathan et al 2011) ${ }^{13}$. Similarly this present study showed an increased incidence of the above cancers in the five year period (2007- 2011). Ovarian cancer and lymphomas have increased in incidence from 1982 to 2006 in Chennai cancer registries (R. Swaminathan et al 2011) ${ }^{13}$. In contrast, this present study showed an increased incidence from 2007 to 2010 followed by decreased incidence in 2011.

In our present study, the incidence of skin cancer, bone cancer and vulval cancers were significantly decreasing in the last five periods (2007 to 2011). Few cancers were maintained the plateau state from 2007 to 2011, which includes endometrial cancers, testicular cancers, bladder cancers and renal cancers.

\section{Summary And Conclusion}

Our study analyzed the total incidence of cancer in Tirunelveli Medical College and Hospital for a period of five years from 2007 to 2011 and classified based on International Classification of Disease for Oncology. This study highlighted the importance of cancer surveillance and ICD-O classification.

The biggest benefit of ICD-O classification dedicated entirely to oncology is that it helps to tackle the serious issues of cancer in a much more efficient manner than before. The International Classification code provides a common platform for researchers and oncologists from all over the world to discuss and share the research information which helps to identify the cause of cancer in a big manner.

Our study concludes that there is significant increase in cancer incidence from base to end (2007 -2011). The incidence of cancer cases increased by $9.6 \%$ totally from base to end. This increase was steady and statistically very highly significant $(\mathrm{P}<0.001)$. The incidence of cancer among the males were increased by $11.6 \%$ and this increase was statistically very highly significant $(\mathrm{P}<0.001)$. The incidence among females, were fluctuating from $62.5 \%$ (2007) to 51.4\% (2011) and this fluctuation was also statistically significant $(\mathrm{P}<0.001)$.

The mean age of cancer incidence among the males and females were 56.9 \pm 12.9 and $52.2 \pm 18.3$.The difference of mean age between males and females was statistically significant $(\mathrm{P}<0.001)$. Comparison between the genders revealed that females had a higher incidence of breast cancer (23.7\%) compared to males (0.8\%) which is statistically significant. Whereas males had greater incidence of cancer in the following sites, such as head and neck, GIT and urinary bladder when compared to females which is statistically significant $(\mathrm{P}<0.001)$. The incidence of thyroid carcinomas among females which is greater than that of males is statistically significant $(\mathrm{P}<0.001)$.

The increasing trends of cancer sites were head and neck, breast, GIT, thyroid, kidney, lymphoma, leukemia, ovary and male genital tract. The fluctuating incidence was noted in the cancer cervix and urinary bladder.

To conclude, our study helps to generate a data about the magnitude and pattern of cancer and helps to undertake epidemiological studies based on these results. In addition, it will help in diagnosing, planning, monitoring and evaluation of cancer control activities.

The ICD-O is a dual classification with coding systems for both morphology and topography. The topography code demonstrates the site of origin of the tumours thereby it increases specificity for coding sites of benign tumours. The morphologic code demonstrates the cell type of the tumour and its biological behaviours. The special topography codes describe the primary malignant tumours according to their origin of tissues/organ. Behaviour code is essential to identify the neoplasms as benign, insitu, primary or secondary. 
"Incidence of Cancer in Tirunelveli Medical College and Hospital-A Five Years Cancer Surveillance ....

This ICD- $\mathrm{O}$ coding helps to face the serious issues of cancer in a much more competent manner and this code helps the researchers and oncologists worldwide to converse and contribute the research information in identifying the cause of cancer in a big way. Further, owing to the classification, oncologists now have a more precise way of knowing whether a tumor is benign or cancerous. This precise distinction itself is the biggest step towards planning and initiating treatment.

\section{References}

[1]. Vinay Kumar, Abul K. Abbas, Nelson Fausto, JonC.Aster. Neoplasia. Robbins and Cotran, Pathologic Basis of Disease. Eighth edition: Elsevier Publ 2010; 259-330.

[2]. Rajesh Dikshit, Chinthanie Ramasundarahettige, Prakash C Gupta, Lukasz Aleksandrowicz, Vendhan Gajalakshmi, Rajesh Kumar, Sandip Roy, Wilson Suraweera, Rajendra Badwe, et al. Cancer mortality in India: a nationally representative survey, March 28, 2012, DOI:10.1016/S0140- 6736(12)60358-4

[3]. Usha K. Luthra, L.D. Sanghvi , A Nandhakumar. Ten-Year Consolidated Report of the Hospital Based Cancer Registries: 1984 - 1993 An Assessment of the Burden and Care of Cancer Patients. National cancer registration programme.

[4]. N.K Ganguly, A. Nandhakumar, Uska K. Luthra, S.K. Battacharya et al. ICMR. National Cancer Registry Programme, Consolidated Report of Population Based Cancer Registries, 2001-2004. Incidence and distribution of cancer, Bangalore, India, 2006.

[5]. World Health Organization, International Classification of disease for Oncology, Third Edition 2000, Geneve.

[6]. World Health Organisation and National Cancer Registry Programme, Atlas of Cancer in India 2009b.

[7]. J.L. Young 1991; Maclennan et al 1978, The hospital-based cancer registry, California Tumor Registry, USA page no 177-184,

[8]. Nandakumar A. National cancer registry program, ICMR, Consolidated report of population based cancer registries:1990-96,New Delhi, India.

[9]. General world cancer statistics, Globocan 2008

[10]. Cancer Stats, Incidence 2009 -UK, Cancer Research UK is a registered charity in England and Wales, Scotland and the Isle of Man , 2012.

[11]. Goodarz Danaei. Global burden of infection -related cancer revisited, 2012 May 9; 1470-2045(12)70176-6.

[12]. A.P. Kurkure, B.B. Yeole, S.S. Koyande, Cancer incidence and mortality in greater Mumbai, Mumbai cancer registry. National Cancer Registry Project, ICMR, 2006.

[13]. R.Swaminathan, V.Shanta, J.ferlay, Balasubramanian, F.Bray, R.Sankaranarayanan, Trends in cancer incidence in Chennai city(19822006) and statewide predictions of future burden in Tamil Nadu(2007-16). The national medical journal of India, 2011; Vol.24: No.2.

[14]. Imran Ali, Waseem A. Wani and Kishwar Saleem. Cancer Scenario in India with Future Perspectives. New Delhi, India. Cancer Therapy,2011; Vol 8, 56-70. 